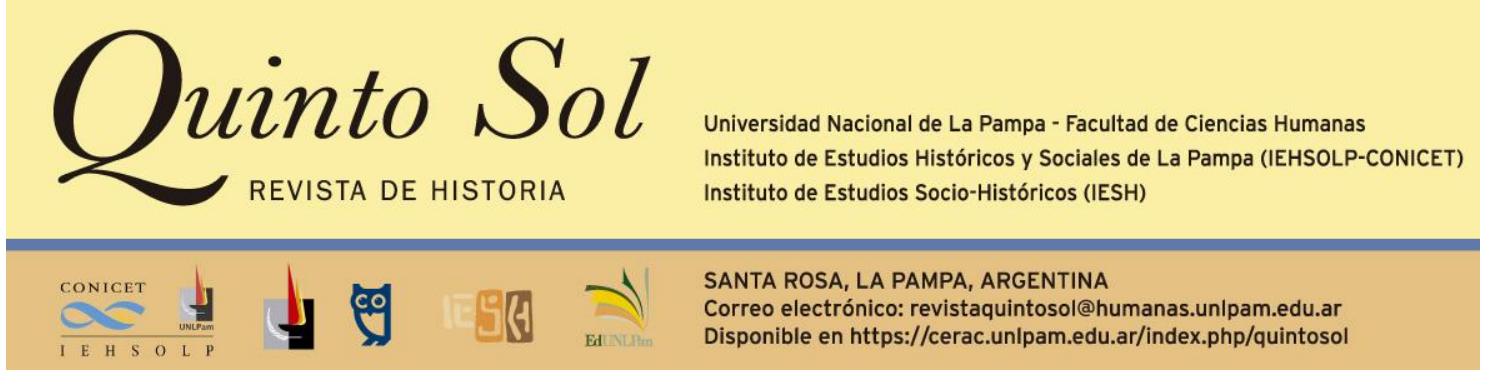

Quinto Sol, vol. 25, n 3, septiembre-diciembre 2021, ISSN 1851-2879, pp. 1-18

https://doi.org/10.19137/qs.v25i3.5261

Esta obra se publica bajo licencia Creative Commons 4.0 Internacional. (Atribución-No ComercialCompartir Igual)

\title{
Partisanismo y populismo: el Comando de Organización en la provincia del Chaco (1973-1976)
}

\section{Partisanship and Populism: the Comando de Organización in the Province of Chaco (1973-1976)}

\section{Partisanismo e populismo: o Comado de Organização na província do Chaco}

\author{
Juan Pedro Denaday \\ Consejo Nacional de Investigaciones Científicas y Técnicas \\ Universidad de Buenos Aires. Instituto de Historia Argentina y Americana "Dr. Emilio Ravignani" \\ Argentina \\ Correo electrónico: juanpedrodenaday@gmail.com
}

\section{Resumen}

Tanto los estudios sobre el peronismo en los espacios subnacionales, como aquellos que abordan la violencia política de los años sesenta y setenta constituyen campos consolidados en la historiografía argentina. En la última década y media se han añadido trabajos en torno a los grupos peronistas opuestos al sector hegemonizado por Montoneros. En esa indagación, diversas investigaciones se detuvieron en escenarios provinciales y locales en los que los conflictos facciosos intraperonistas se desarrollaron con intensidad. En el cruce de esas inquietudes historiográficas, el presente artículo repara en el caso del Comando de Organización de la provincia del Chaco durante el período 1973-1976, y se focaliza en dos problemas conceptuales. El primero, siguiendo algunas

Palabras clave partisanismo peronismo violencia política 
claves teóricas provistas por la teoría del partisano de Carl Schmitt, plantea una caracterización del tipo de violencia política ejercida por esta agrupación. La segunda cuestión remite a la discusión en torno a la utilidad del uso de la categoría derecha peronista para definir a los diversos actores antimontoneros. A esos fines se cotejan los planteos ideológicos del Comando chaqueño con los que tradicionalmente sostenía el populismo peronista.

\section{Abstract}

Studies about Peronism at subnational levels as well as research addressing the political violence in the sixties and seventies are consolidated fields in Argentinian historiography. Furthermore, articles on Peronist groups that opposed the sector led by Montoneros have been published in the last fifteen years. In that line of inquiry, various investigations have considered provincial and local settings where intense factional conflicts arose inside the Peronist party. At the intersection of those historiographical questions, this research centers on the case of the Comando de Organización in the Province of Chaco during the period 1973-1976 and focuses on two conceptual issues. The first one, in line with some key theoretical principles provided by Carl Schmitt's Theory of the Partisan, poses a description of the type of political violence inflicted by this organization. The second issue refers to the discussion about the use of the term right-wing Peronism to define diverse anti-Montoneros actors. To this end, the ideological propositions of the Comando in Chaco are compared with the ideas traditionally held by the Peronist populism.

\section{Resumo}

Tanto os estudos sobre o peronismo nos espaços subnacionais como aqueles que abordam a violência política dos anos sessenta e setentas constituem áreas consolidadas na historiografia argentina. Na última década e meia se incluem trabalhos sobre os grupos peronistas opostos ao setor hegemonizado por Montoneros. Nessa indagação, diversas investigações se deteram em cenários provinciais e locais nos quais os conflitos partidários intraperonistas se desenvolveram com intensidade. $\mathrm{Na}$ intersecção dessas inquietudes historiográficas, o presente artigo põe o foco no caso do Comando de Organização da província do Chaco durante o período 1973-1976 e se focaliza em dois problemas conceituais. O primeiro, seguindo algumas chaves teóricas outorgadas pela teoria do partisano de Carl Schmitt, expõe uma caracterização do tipo de violência exercida por esta agrupação. A segunda questão remete à discussão sobre a utilidade do uso da categoria direita peronista para definir os diversos atores antimontoneros. Sob esses focos se comparam as propostas ideológicas do Comando chaqueño com os que tradicionalmente se sustenta o populismo peronista.

\section{Key words}

partisanship peronism political violence

Palavras-chave partisanismo peronismo violência política 


\section{Partisanismo y populismo: el Comando de Organización en la provincia del Chaco $(1973-1976)^{1}$}

\section{Introducción}

Los estudios sobre el peronismo en las provincias constituyen un campo de investigaciones consolidado en la historiografía local. A los trabajos referidos a los orígenes y el primer peronismo (Macor y Tcach, 2013, 2014), se han sumado algunos sobre el período 1973-1976. Cabe destacar el libro de Alicia Servetto (2010), que dio cuenta de cómo las pujas facciosas, el desplazamiento de gobernadores y las intervenciones federales incidieron decisivamente en las dinámicas políticas de aquellas provincias en las que la Tendencia Revolucionaria tenía una incidencia institucional significativa. ${ }^{2}$ Hasta el momento, la bibliografía disponible no ha llegado a abarcar todo el mapa argentino, ni se ha detenido con igual profundidad en los distintos períodos. El territorio en el que repara este artículo -la provincia del Chaco- presenta para la historia política del período 1955-1976 un marcado vacío historiográfico. El primer aporte del presente texto radica, por tanto, en una contribución parcial para colaborar en la tarea de llenarlo. En particular, el artículo facilita una primera aproximación a los conflictos intraperonistas suscitados durante la última gobernación de Deolindo Felipe Bittel.

En la última década y media se aprecia un avance de estudios especializados en torno a aquellas agrupaciones peronistas que mantuvieron una lucha política con la izquierda. Siguiendo esta línea historiográfica, el presente artículo expone los resultados de una investigación sobre el Comando de Organización (CO) en la provincia del Chaco durante el trienio justicialista de los setenta. Haciendo foco en esta agrupación, con el recorte temporal y espacial antedicho, se abordó el objeto a partir de la formulación de dos problemas. El primero de ellos se interesa en el análisis de la violencia política desde claves teóricas provistas por la teoría del partisano de Carl Schmitt. ¿Qué tipo de partisanismo ejercitaron los miembros del CO chaqueño? ¿Qué nos puede iluminar este caso sobre el fenómeno de la violencia política argentina durante el primer lustro de los años setenta? El segundo asunto remite a la discusión acerca del uso de categorías para ubicar a los diversos actores peronistas de los años setenta. ¿Resulta ilustrativa la díada izquierda-derecha para dar cuenta del conflicto intraperonista de los setenta? ¿Qué nos revela sobre esta cuestión el análisis de la posición político-ideológica del CO chaqueño?

Las fuentes primarias consultadas corresponden mayoritariamente a la prensa escrita, en particular a los dos diarios a la sazón de mayor circulación en la provincia: El

\footnotetext{
${ }^{1}$ Agradezco por su dedicada labor a los evaluadores anónimos, al Comité Editor y a los asistentes de la revista.

${ }^{2}$ Otro conjunto de trabajos, que sería extenso citar aquí, han reparado en diversos escenarios de violencia política a nivel subnacional.
} 
Territorio y Norte. ${ }^{3}$ Como lo han indicado María Solís Carnicer y Mayra Maggio (2019), la prensa escrita es una fuente ineludible para la mayoría de los estudios de historia regional, pero su uso demanda ciertas precauciones metodológicas. Básicamente porque el historiador debe tener en cuenta tanto la representación de la realidad hecha por los redactores, como su propia subjetividad al momento de interpretar esos textos (p. 153). Aun cuando se advierte cierto sesgo en la línea editorial, más cercana al radicalismo en Norte y más afín al peronismo en El Territorio, lo cierto es que sobre todo este último diario acostumbraba a reproducir discursos literales y a publicar documentos enviados a la redacción, como ocurrió con muchos textos de la Juventud Peronista (JP) y del CO. Esto nos facilitó el acceso a algunas fuentes primarias sin mediar una intervención periodística que pudiera considerarse decisiva.

\section{Comandos y montoneros en el gobierno de Deolindo Bittel}

En 1884, el Estado argentino sancionó una ley que sumó a las catorce provincias históricas -en forma dependiente del poder central y con derechos políticos restringidos para sus habitantes- a los territorios nacionales de Chaco, Misiones, Formosa, La Pampa, Río Negro, Neuquén, Chubut, Santa Cruz y Tierra del Fuego (Bucciarelli, 2009). Recién bajo el gobierno de Juan Domingo Perón estos territorios fueron habilitados para participar de las elecciones presidenciales $y$, con excepción de Tierra del Fuego, fueron provincializados. El del Chaco en 1951 pasó a denominarse provincia Presidente Perón (Ruffini, 2005).

Desde 1910 y hasta el surgimiento del peronismo en el Chaco hacían política partidaria la Unión Cívica Radical (UCR) y el Partido Socialista (PS), y en 1946 se conformaron el Partido Comunista (PC) y la Democracia Progresista (Leoni y Solís Carnicer, 2015, p. 72). En las elecciones nacionales del 11 de noviembre de 1951, el peronismo compitió con ellos y alcanzó un abrumador $81 \%$ de los votos. Inspirándose en los principios de la nueva Constitución nacional sancionada dos años antes, en 1951 se promulgó en el Chaco una Constitución provincial, cuya novedad más destacable radicó en el artículo 33. Dado que este definía que la mitad de los representantes serían de las asociaciones profesionales, los radicales y los socialistas tacharon a la Constitución de "corporativista, fascista y anticonstitucional" (Leoni y Solís Carnicer, 2015, p. 74-75). Consecuentemente, esos partidos se abstuvieron de participar en las elecciones de abril de 1953, en las que solo el PC presentó lista opositora. La fórmula peronista conformada por Felipe Gallardo, de extracción sindical, y Deolindo Felipe Bittel, proveniente de la rama política, triunfó y obtuvo todos los legisladores nacionales y provinciales (Maeder, 1996, p. 236).

En la etapa posterior al golpe militar de 1955, el exvicegobernador Bittel se consolidó como el dirigente más importante del peronismo chaqueño. Después de sucesivas intervenciones militares y de la gobernación del radical intransigente Anselmo Zoilo Duca, Bittel se encontró entre aquellos candidatos justicialistas que ganaron las elecciones de marzo de 1962, ${ }^{4}$ rápidamente anuladas por Arturo Frondizi bajo presión militar (Arias y Heras, 1993, pp. 106-107). De la mano del partido

\footnotetext{
3 También se ha recurrido a entrevistas y testimonios; por razones de espacio omitimos reiterar consideraciones metodológicas en torno a un tema trajinado.

${ }^{4}$ En estas elecciones legislativas se permitieron candidaturas de los partidos neoperonistas.
} 
neoperonista Unión Popular del Chaco, que estableció una alianza con el Partido Conservador, Bittel finalmente llegó a la gobernación el 12 de octubre de 1963. En segundo lugar se ubicó el radicalismo balbinista, que luego, en los comicios legislativos de 1965, consolidó dicha posición. En consonancia con lo que acontecía en el orden nacional, Bittel debió entregar el gobierno al triunfar el golpe militar de Juan Carlos Onganía. Luego de las intervenciones castrenses, durante la llamada Revolución Argentina, Bittel volvió al poder el 25 de mayo de 1973 (Maeder, 1996, pp. 249-260).

El Frente Justicialista de Liberación -FREJULI-, con la fórmula Bittel-Torresagasti a la cabeza, ganó las elecciones del 11 de marzo de 1973 al cosechar el 56,14\% de los sufragios con 133.481 votos. La UCR consiguió 64.840 votos, lo que arrojó para la fórmula Salom-Janik un porcentaje del 27,27\%. La Alianza Popular Federalista quedó en tercer lugar con solo el $7,11 \%$ y los demás partidos ${ }^{5}$ recogieron guarismos poco representativos (Maeder, 1996, p. 259). Así, de los treinta diputados que pasaron a integrar la Cámara del Poder Legislativo unicameral, veinte pertenecían al justicialismo y diez al radicalismo. ${ }^{6}$ En cuanto a los fenómenos sociales con impacto en la arena política, se advierte en el Chaco de los setenta un estado de movilización entre los estudiantes universitarios, los productores y los trabajadores agrícolas. Este último movimiento social fue canalizado principalmente a través de las Ligas Agrarias y organizaciones que representaban a los pueblos originarios. El movimiento indígena chaqueño se encontraba disputado centralmente entre los grupos que respondían a la monja Guillermina Hagen (Montoneros) y quienes adherían a las políticas públicas impulsadas por René James Sotelo, a cargo de la Dirección Provincial del Aborigen ${ }^{7}$ desde 1971. Fundador de la Asociación Amigos del Aborigen a comienzos de los sesenta, Sotelo era un reconocido indigenista y gremialista docente que desarrollaba desde hacía años un trabajo de alfabetización en el sector. ${ }^{8}$

En lo que hace a la militancia juvenil, barrial y los espacios de poder gubernamental, las principales organizaciones que activaron la puja intraperonista fueron los Montoneros, las Fuerzas Armadas Peronistas-Peronismo de Base (FAP-PB) y el CO. La JP tenía numerosos grupos diseminados en el interior chaqueño y en otras agrupaciones nacionales, como el Encuadramiento de JP (los Demetrios), donde también tenían influencia. Pero la disputa central fue entre la JP Regionales, liderada por Guillermo Amarilla, un estudiante universitario proveniente del integralismo, y el $\mathrm{CO}$, conducido por Víctor Sánchez, un locutor de radio y activista peronista.

El CO había sido fundado en Buenos Aires a comienzos de los sesenta y quedó bajo el liderazgo personalista de Alberto Brito Lima. Esta agrupación cultivó un perfil radicalizado y logró un implante territorial en algunos barrios populares de la Capital Federal y el conurbano bonaerense (Denaday, 2016). En octubre de 1965, cuando Estela Martínez (más conocida como Isabel Perón) visitó el país, los jóvenes del CO la custodiaron en Buenos Aires y en su gira por el interior del país, incluido el Chaco, donde Bittel organizó un multitudinario recibimiento (Marcilese, 2017, p. 21). Tanto durante esa gira, como en congresos de la JP que organizó en distintas provincias y

\footnotetext{
${ }^{5}$ PS, Partido Conservador, Alianza Intransigente, Nueva Fuerza y Frente de Izquierda Popular.

${ }^{6}$ Radiografía de la Legislatura chaqueña (7 de abril de 1973). El Territorio, pp. 7-8. Archivo Histórico Monseñor José Alumni, Resistencia, Chaco, Argentina.

${ }^{7}$ Organismo entonces dependiente del Ministerio de Bienestar Social del Chaco.

${ }^{8}$ Sobre la vida de René Sotelo ver Matilde Michanie (2018). La comunicadora social Melisa Sotelo le facilitó al autor los apuntes de la investigación que realizó para el documental.
} 
localidades, el CO logró cierta extensión nacional. En algunas provincias en particular consiguió una presencia militante de cierta importancia. Aunque desconocemos los pormenores de cómo se trabó la relación, uno de esos vínculos que estableció Brito Lima fue con el chaqueño Víctor Sánchez, con quien mantuvo, desde mediados de los sesenta, una relación política especialmente cercana. ${ }^{9}$

Hacia el año 1972, cuando las noticias relativas a la JP comenzaron a hacerse más visibles en la prensa chaqueña, Víctor Sánchez, quien tenía entonces 32 años, dirigía la estructura militante del peronismo tradicional más extendida territorialmente. El CO tenía influencia en la cúpula del Partido Justicialista (PJ) local y era cercano al sector político del ministro de Gobierno Florencio Tenev. ${ }^{10}$ Otras figuras de peso en el gobierno eran también firmes aliados del $\mathrm{CO}$, como el ministro de Bienestar Social Ezequiel Morante, en cuya secretaría privada fue designado Sánchez. Lo mismo ocurría con los funcionarios Daniel Pacce y Guillermo Codina, en cuya secretaría privada fue designado Juan Carlos Gómez, el segundo dirigente más importante del CO chaqueño. Asimismo, el CO mantenía una relación cercana con Deolindo Bittel. En el congreso de la JP que el CO realizó una semana antes de asumir la gestión justicialista, el mandatario electo se sentó en la mesa de conducción junto a Sánchez y pronunció un discurso. ${ }^{11}$ Al parecer, Montoneros resultó desfavorecido en el reparto de cargos y, aunque dirigió algunas subsecretarías, ocupó posiciones menos relevantes en la estructura burocrática del gobierno local. ${ }^{12}$

En 1973 y 1974 el peronismo se mostró activo y dividido entre el oficialismo y la disidencia montonera. Al igual que aconteció en el orden nacional, en 1974 se desarrolló un proceso durante el cual la violencia armada fue desplazando progresivamente a la política del centro de la escena pública. La guerrilla chaqueña de signo peronista (también actuaba el Ejército Revolucionario del Pueblo) estuvo estrechamente vinculada a sectores católicos y al ámbito universitario, su represión provino principalmente del CO y la policía. Hacia 1975 el peronismo comenzó a perder la iniciativa política mientras adquirían creciente protagonismo fuerzas opositoras como la UCR, el empresariado y las Fuerzas Armadas, quienes tomaron el poder en marzo de $1976 .^{13}$

\section{Los partisanos del CO chaqueño}

Carlos Altamirano (2011) distingue la estrategia política montonera de aquellas que resultaban más habituales en la tradición de izquierdas. Mientras estas solían definir las oposiciones políticas a partir de las contradicciones sociales, los jóvenes guerrilleros argentinos hicieron una apuesta diferente al proponerse "insertarse como partisanos en la dicotomía peronismo/antiperonismo" (p. 155). La teoría de Carl Schmitt (2013) permite interpretar el conflicto intraperonista entre grupos de irregulares

\footnotetext{
${ }^{9}$ Pedro Bevilacqua, dirigente del CO. Entrevista realizada por el autor el 12 de noviembre de 2012 en la Ciudad Autónoma de Buenos Aires (CABA), Argentina.

${ }^{10}$ Sería electo gobernador al recuperarse la democracia en 1983.

${ }^{11}$ La Juventud Peronista eligió en Sáenz Peña sus nuevas autoridades (21 de mayo de 1973). El Territorio, p. 3.

${ }^{12}$ Aníbal Ponti, dirigente montonero del Chaco. Entrevista realizada por Marcos Salomón y Gonzalo Torres el 5 de diciembre de 2010 en la ciudad de Resistencia, Chaco. http://yofuimontonero.blogspot.com/

${ }^{13}$ Intervención en el Chaco: Asumió coronel Zucconi (25 de marzo de 1976). Norte, p. 2. Archivo Histórico Monseñor José Alumni.
} 
armados bajo una dinámica transversal de partisanismo. Si bien dicha teoría no omite las posibles y distintas relaciones que el partisano puede establecer con las fuerzas armadas regulares, lo que distingue a esta figura es su carácter de combatiente irregular dotado de un alto compromiso político. El jurista alemán señala que la propia palabra partisano "se deriva de partido": "partisano quiere decir partidario, uno que va con un partido". Así, la motivación del partisano debe distinguirse conceptualmente de la del mero delincuente, lugar que en el derecho marítimo ocupa la figura del pirata, un combatiente apolítico solo interesado en el robo y la ganancia personal (p. 32).

Desde que el movimiento que lideraba regresó al gobierno, Perón sostuvo que los guerrilleros debían abandonar las armas para incorporarse a la vida constitucional. En la medida que comenzó a hacerse evidente que eso no ocurriría, su discurso en torno a cómo combatir a la guerrilla fue ambiguo. Por un lado, insistió en que esta constituía "un problema policial", lo que dejaba a sus miembros en una posición delincuencial que, como cualquier otra, debía ser reprimida por las fuerzas de seguridad dentro del marco legal. Pero por otro, amenazó con emplear procedimientos irregulares y en más de una ocasión los promovió y avaló tácitamente. ${ }^{14}$ La designación de Alberto Villar como jefe de la Policía Federal a comienzos de 1974 resultó reveladora de la ambigüedad de Perón. Villar, un profesionalista políticamente más vinculado al radicalismo, ${ }^{15}$ era para entonces un reconocido experto en la represión antiguerrillera. Esos resultados exitosos eran fruto de que, tal como lo recomendaban los manuales de guerra contrarrevolucionaria, sus policías motorizados combinaban los procedimientos regulares con los irregulares.

El CO estableció un vínculo con el comisario Villar ${ }^{16}$ y se ubicó en esa misma posición ambigua. Por un lado, se resistieron a volcarse a una lucha abierta e ilegal contra la guerrilla ${ }^{17}$ y, luego de la muerte de Perón, se negaron a alinearse con José López Rega y la Triple A. ${ }^{18}$ Por ese motivo, Brito Lima se separó de su histórica aliada, Norma Kennedy, y cuando uno de los cuadros del CO, Osvaldo "Paqui" Forese, propuso sumarse al esquema de represión de esas bandas clandestinas, Brito Lima lo expulsó de la agrupación. ${ }^{19}$ Sin embargo, esto no fue en detrimento de que, en simultáneo con el

\footnotetext{
14 Podrían citarse varios discursos de Perón, pero especialmente elocuente resulta el "Documento Reservado", emitido oficialmente por las autoridades partidarias justicialistas luego del asesinato de José Rucci. El documento instaba a los peronistas a utilizar "todos los medios de lucha" contra la "infiltración" de "grupos marxistas". $1^{\circ}$ de octubre. Consejo Superior Peronista (octubre de 1973). Boletín de Difusión Interna, Encuadramiento de la Juventud Peronista, $N^{\circ} 4$, p. 8. Archivo personal del autor, CABA. El dirigente del PC Fernando Nadra se preguntaba retóricamente si esos métodos avalados eran los que "emplean Brito Lima y los jerarcas sindicales". Peligroso "Documento Reservado" (10 de octubre de 1973). Editorial de Nuestra Palabra reproducido en Fernando Nadra (1974, p. 82).

15 Provenía de un grupo de policías formados en el período presidencial de Arturo Illia, cuando habían tenido por jefe al inspector Nicolás Rodríguez. La policía frente a la violencia (7 de febrero de 1974). Última Clave, Año VII, N 177, p. 2. Hemeroteca, Biblioteca Nacional, CABA.

${ }^{16}$ Brito Lima recuerda al comisario como "un hombre de la fuerza", pero fue un "amigo en la lucha" y "nos dio 200 ametralladoras Halcón". Alberto Brito Lima, líder del CO. Entrevista realizada por Pablo Anzaldi, sin indicación de lugar ni fecha (Anzaldi, 2016, p. 205).

17 Dirigentes más militaristas, como Juan Quiróz, cuestionaron a Brito Lima por pretender seguir en un debate ideológico cuando se estaba frente a una confrontación armada. Juan Quiróz, dirigente del CO. Entrevista realizada por el autor el 21 de enero de 2014 en CABA.

${ }^{18}$ Alianza Anticomunista Argentina (AAA).

${ }^{19}$ Los testimonios de excuadros que participaron del congreso del CO del que Forese fue expulsado son coincidentes. Roberto Surra recuerda que Brito Lima discutió duramente con Forese, a quien habría acusado de "cobarde" por "pegarle a gente atada con alambre", en referencia a que Forese participaba de
} 
apoyo a la represión policial, el CO realizara sus propias acciones irregulares. Teniendo en cuenta esta posición nacional de la agrupación, podemos ahora detenernos en los hechos de violencia política que protagonizó en el Chaco.

Los militantes del CO tuvieron una participación protagónica en el enfrentamiento armado ocurrido el 20 de junio de 1973 en las inmediaciones del palco montado en Ezeiza, Buenos Aires. El CO chaqueño promovió la movilización y tuvo a su cargo la flota de colectivos del PJ que partió desde Resistencia. Luego del hecho armado, la Mesa Provincial del CO chaqueño emitió un comunicado en el que les otorgaba a sus militantes, "sin distinción de jerarquía ni función", la mención de honor "Soldados de Ezeiza". ${ }^{20}$ Cuando militantes chaqueños de Montoneros realizaron la pegatina de los afiches que denunciaban a "los asesinos de Ezeiza", con las fotos de Jorge Osinde, ${ }^{21}$ Norma Kennedy ${ }^{22}$ y Brito Lima, se produjo un tiroteo de varias horas de duración con el $\mathrm{CO}$, que solo cesó al hacerse presentes diputados peronistas y efectivos de la policía local. ${ }^{23}$

Durante agosto y septiembre de 1973, el CO chaqueño fue objeto de múltiples denuncias por acciones violentas. ${ }^{24}$ El 7 se septiembre, cuando Isabel arribó a la provincia para participar del acto de lanzamiento de la fórmula Perón-Perón, los hombres del CO garantizaron su custodia personal. ${ }^{25}$ A su vez, fueron los encargados de la seguridad del acto y en el ingreso al estadio se vivieron momentos de tensión con los activistas promontoneros. ${ }^{26}$ La Tendencia Revolucionaria nutrió sus columnas con militantes de la JP Regionales, de la Juventud Universitaria Peronista (JUP) y de la Federación Indígena del Chaco. Estos manifestantes se movilizaron luego hacia la casa de Gobierno para exigir la destitución de René James Sotelo. ${ }^{27}$ Luego de una infructuosa reunión con Bittel, los manifestantes siguieron protestando en la calle y fueron rodeados por la policía, los bomberos y el $\mathrm{CO}^{28} \mathrm{~A}$ la noche, un centenar de comandos salieron de uno de los patios interiores de la Casa de Gobierno y atacaron a un grupo del PB. Los militantes del CO realizaron disparos al aire y se ocasionaron

operaciones de secuestro y tortura de militantes. Roberto Surra, dirigente del CO. Entrevista realizada por el autor el 6 de agosto de 2018 en CABA.

20 Juventud Peronista: Comando Organización (3 de julio de 1973). El Territorio, p. 9.

${ }^{21}$ Militar de inteligencia y estrecho colaborador de Perón desde su primer gobierno, el 20 de junio de 1973 fue el encargado de la seguridad oficial.

${ }^{22}$ Militante de origen comunista y luego del activismo de la Resistencia peronista, tuvo ascendiente en la rama femenina y fue, hasta la muerte de Perón, aliada de Brito Lima.

${ }^{23}$ Aníbal Ponti, dirigente montonero del Chaco. Entrevista realizada por el autor el 12 de septiembre de 2016 en la ciudad de Resistencia.

24 Intimidación armada (2 de agosto de 1973). El Territorio, p. 9. La Juventud Radical formuló denuncias contra el Comando de Organización (19 de septiembre de 1973). El Territorio, p. 3. El FIP denuncia (20 de septiembre de 1973). Norte, p. 6.

25 Multitudinario acto de proclamación peronista con la presencia de Isabel (8 de septiembre de 1973). Norte, p. 2.

${ }^{26}$ Hondo fervor popular en el acto de proclamación del binomio peronista (8 de septiembre de 1973). El Territorio, p. 1.

${ }^{27}$ René Sotelo no era peronista y su único vínculo partidario había sido con el frondicismo inicial, cuando, como muchos otros intelectuales, se vio entusiasmado y rápidamente defraudado. Su hermano, Rubén Sotelo, figura saliente de la élite partidaria justicialista, había sido ministro durante el primer Gobierno peronista y era entonces el presidente de la Cámara de Diputados local.

${ }^{28}$ Hubo un áspero diálogo con Bittel (8 de septiembre de 1973). Norte, p. 2. 
corridas y luchas físicas. ${ }^{29}$ Terminados los incidentes, el CO e indígenas oficialistas se movilizaron hasta la casa del gobernador Bittel, quien improvisó un discurso en la puerta. $^{30}$ Esta secuencia de hechos hacía visible la estrecha colaboración que existía entre los partisanos del $\mathrm{CO}$, las fuerzas policiales y la plana mayor del gobierno provincial.

El 18 de septiembre de 1973, miembros del CO encabezados por Sánchez ingresaron en el comedor universitario de la Facultad de Humanidades realizando disparos al aire. Luego, golpearon y amenazaron a activistas universitarios y a militantes de la Juventud Radical. ${ }^{31} \mathrm{El}$ hecho concitó un amplio repudio entre el activismo estudiantil, que realizó una movilización hacia la Casa de Gobierno para reclamar medidas contra el $\mathrm{CO}^{32}$ En contraste, tanto el discurso televisivo de Bittel ${ }^{33}$ como las declaraciones del juez actuante en la causa, José Rinessi, revelaban que el CO contaba con la anuencia de las autoridades de esos poderes del Estado. Este último, quien había dictado la libertad para Sánchez y los demás detenidos, ante una pregunta sobre la falta de garantías, contestó que "todos, en general, tenemos una falta de garantías". ${ }^{34}$ De este modo, el accionar del CO quedaba naturalizado en el marco de un argumento que planteaba la existencia de hecho de una suerte de estado de excepción.

El cambio más importante fue que, luego del ataque al comedor universitario, tal como lo había anticipado Bittel en el discurso mencionado con anterioridad, la represión pasó a estar monopolizada por la policía. Aunque se suscitaron nuevos incidentes con personal del diario El Territorio y con militantes del Frente de Izquierda Popular, ${ }^{35}$ después del asesinato de José Ignacio Rucci-que concitó en la provincia un paro general y un acto masivo- ${ }^{36}$, el nuevo contexto que emergió tras ese acontecimiento nacional pasó a un segundo plano el accionar del CO chaqueño.

Al igual que aconteció en el orden nacional, durante 1974 la violencia política experimentó en el Chaco un salto cualitativo. Se registraron ataques guerrilleros de mayor envergadura, ${ }^{37}$ y las detenciones y allanamientos policiales se volvieron más

\footnotetext{
${ }^{29}$ Argentina montonera. Chaco. Policías y matones contra el pueblo (20 de septiembre de 1973). Militancia, $\mathrm{N}^{\circ}$ 15, p. 38. Hemeroteca, Biblioteca Nacional. Manifestación: Se vivieron momentos tensos. Hubo incidentes (9 de septiembre de 1973). El Territorio, p. 2.

${ }^{30}$ Segunda manifestación: Del Comando y aborígenes (14 de septiembre de 1973). El Territorio, p. 2.

31 Detalles del atentado perpetrado en el comedor universitario de Resistencia (19 de septiembre de 1973). El Territorio, p. 2. Un grupo armado atacó a tiros ayer a estudiantes en el comedor de la UNNE (19 de septiembre de 1973). El Territorio, p. 1. La Juventud Radical denunció haber sido objeto de una agresión (19 de septiembre de 1973). Norte, p. 1.

32 Intensa repercusión del atentado del martes. Voces de repudio. Asamblea en la UNNE. Víctor Sánchez sigue detenido (20 de septiembre de 1973). Norte, p. 12.

${ }^{33}$ Chaqueñadas (21 de septiembre de 1973). Norte, p. 6.

${ }^{34}$ Atentado al comedor. Confirmó el juez federal al periodismo que no existe ninguna persona detenida (23 de septiembre de 1973). Norte, p. 2.

${ }^{35}$ Nueva manifestación contra el Comando (25 de septiembre de 1973). Norte, p. 8. Amenazan volarle el local al FIP. Una nueva denuncia contra el Comando de Organización (30 de septiembre de 1973). Norte, p. 9.

${ }^{36}$ Numerosa concurrencia tuvo el homenaje chaqueño a José Rucci. Lo promovió la CGT y participó el gobernador Bittel (28 de septiembre de 1973). Norte, p. 10.

37 El 29 de enero se intentó tomar la delegación Resistencia de la Policía Federal y el 15 de abril Montoneros hizo lo propio con el destacamento policial de Colonia Aborigen. Copamiento frustrado (30 de enero de 1974). Norte, p. 1. Sacerdotes implicados en el audaz golpe extremista de ayer (1974, abril 16). Norte, p. 2.
} 
frecuentes. $^{38}$ No tenemos datos que certifiquen la participación del $\mathrm{CO}$ en los operativos policiales, pero su colaboración no sería extraña, en tanto el crecimiento de la persecución contra la guerrilla estaba en línea con lo que acontecía a nivel país después del ataque al cuartel de Azul, cuando Perón endureció su discurso y rehabilitó en funciones a Villar. Según Ponti, la decisión de ejecutar a Sánchez la tomaron por el constante hostigamiento que sufrían de parte del $\mathrm{CO}$, cuyos miembros colaboraban con la policía en la persecución de los militantes montoneros. ${ }^{39}$

A comienzos de 1974, una explosión en la casa de la madre de Sánchez destruyó su vivienda y la hirió de muerte. Aunque circularon diferentes versiones sobre si el hecho fue accidental o provocado, ${ }^{40}$ lo destacable es que el sepelio de Ambrosia Pavón se transformó en un acontecimiento político. Luego de ingresar la "extensa caravana" al cementerio del Oeste, Brito Lima pronunció un discurso. ${ }^{41}$ Lo escuchaba una "multitudinaria concurrencia" y el gobernador Bittel, quien había tomado una de las manivelas del féretro. Solo una semana después de anunciar su pase a la clandestinidad, ${ }^{42}$ el 13 de septiembre de 1974, Montoneros asesinó a Sánchez. ${ }^{43}$ En el operativo también fue ejecutado otro militante del CO, Félix Saucedo, y resultó gravemente herido Gabriel Oscar Benítez, un empleado de Radio Corrientes. ${ }^{44}$ La cobertura periodística de Norte reparó tanto en la trayectoria de Sánchez como dirigente político y locutor de radio como en los hechos de violencia que había protagonizado y las armas que se encontraron en su automóvil. ${ }^{45}$ En una entrevista radial, Bittel manifestó su dolor al ver caer por "las balas de mercenarios" a "un muchacho que conozco desde hace muchos años, de una larga militancia", y convocó de modo insistente a mantener una actitud pacífica. ${ }^{46}$ En enero de 1975, varios militantes montoneros fueron detenidos por su presunta participación en el asesinato de Sánchez. ${ }^{47}$

En la teoría del partisano de Schmitt (2013) buscamos algunas claves para pensar una figura de morfología variada e imprecisa, y que resultó decisiva en las luchas políticas del siglo XX. La ambigüedad del partisano está dada, entre otras

\footnotetext{
${ }^{38}$ La Tendencia de JP denuncia detenciones (10 de marzo de 1974). Norte, p. 8. ¿Apremios ilegales? (2 de abril de 1974). Norte, p. 21. Hay cien detenidos (17 de abril de 1974). Norte, p. 3.

${ }^{39}$ Aníbal Ponti, dirigente montonero del Chaco. Entrevista realizada por el autor el 12 de septiembre de 2016 en la ciudad de Resistencia.

40 ¿Garrafa o bomba? (9 de enero de 1974). Norte, p. 1.

${ }^{41}$ Inhumaron ayer los restos de la madre de Víctor Sánchez (19 de enero de 1974). Norte, p. 7.

42 La Tendencia cerró sus locales en todo el país (9 de septiembre de 1974). Norte, p. 3.

${ }^{43}$ Víctor Sánchez asesinado (14 de septiembre de 1974). El Territorio, p. 1. Acribillaron a Víctor Sánchez (14 de septiembre de 1974). Norte, p. 1.

${ }^{44}$ El Chrysler Valiant de Sánchez fue interceptado por dos automóviles luego de cruzar el puente que une a las provincias de Corrientes y Chaco, desde una camioneta F100 se descargó una profusa balacera con armas automáticas. Los guerrilleros bajaron de la camioneta para dar el tiro de gracia a los heridos, pero Benítez, aun con secuelas graves para su salud, logró sobrevivir. Seis balazos recibió Benítez. Fue sometido a una operación quirúrgica. Evoluciona favorablemente (14 de septiembre de 1974). El Territorio, p. 2.

${ }^{45}$ Acribillado a balazos murió Víctor Sánchez (14 de septiembre de 1974). Norte, pp. 5-6.

${ }^{46}$ El gobernador Bittel condenó el atentado de que fue víctima el dirigente peronista (14 de septiembre de 1974). El Territorio, p. 1. El camino argentino no pasa por la violencia (1974, septiembre 14). El Territorio, p. 2.

${ }^{47}$ Aunque vimos que la explicación de Ponti era otra, Montoneros realizó más tarde una reivindicación del asesinato como parte de las represalias por la "masacre de Ezeiza", que incluyeron también a otros dirigentes del CO. Justicia Popular (junio-julio de 1975). Evita Montonera, Revista oficial de Montoneros, Año 1, No 5, p. 18. http://www.ruinasdigitales.com/
} 
razones, porque en él "los antagonismos regular-irregular y legal-ilegal suelen cruzarse y desdibujarse" (p. 34). Esta posición distinguió a los partisanos del CO, quienes, aunque transgredieron el "acotamiento" del derecho de guerra clásico, no ingresaron en el "círculo de terror y contraterror hasta la aniquilación total" (p. 29). Se advierte que los combatientes del CO no llevaron el partisanismo a su máxima expresión terrorista, y es esa posición relativamente más contenida la que permite diferenciarlos de otros grupos de irregulares. El caso del CO chaqueño resulta elocuente al respecto, en tanto si bien sus miembros, como vimos hicieron uso de armamento, amedrentaron y hostigaron a diversos sectores opositores, es un dato a considerar que en esas incursiones violentas no asesinaron ni hirieron de gravedad a personas. Asimismo, cuando su máximo dirigente fue ejecutado, se abstuvieron de tomar represalias y recurrieron a las vías legales. ${ }^{48}$

\section{El CO chaqueño y la tradición ideológica del populismo peronista}

En el apartado anterior nos detuvimos en las prácticas partisanas del $\mathrm{CO}$, pero igual de importante es reparar en que, tal como acontecía en el orden nacional, el repertorio de prácticas políticas de esta agrupación era variado y sería un equívoco caracterizarlo como un "grupo de choque", ${ }^{49}$ si por esto se entiende una tropa de acción despreocupada de las ideas políticas. Por el contrario, a tono con el clima de época, el CO era un grupo que entendía su accionar político como férreamente situado dentro de un dogma ideológico. Se trataba de la denominada Doctrina Peronista, que para ellos operaba como una suerte de cuerpo filosófico-político de alcance existencial. Por tanto, los comandos le otorgaban un lugar destacado a las tareas de propaganda política, formación ideológica y difusión cultural, y a esos fines fundaron en el Chaco el Comando de Adoctrinamiento de la JP, que dictaba sus clases en el local central del PJ y en otras localidades del Gran Resistencia y el interior chaqueño. ${ }^{50}$ La convivencia de estas facetas no es teóricamente contradictoria, porque ya mencionamos que lo que distingue al partisano es precisamente su alto nivel de compromiso político. Interrogarse, entonces, en torno a la trama de discursos y concepciones en que se inscribía el accionar del CO adquiere una importancia para interpretar la agrupación y la relación que mantenía con la identidad peronista. Antes de analizar el caso chaqueño, para fundamentar nuestra perspectiva introducimos algunas consideraciones más generales.

María Matilde Ollier (2006) sostiene que el "peronismo revolucionario"51 se enfrentó a la necesidad de inventar un peronismo que alteraba de modo evidente su historia y sus parámetros ideológicos tradicionales. Aunque estas operaciones fueron más claras en las Fuerzas Armadas Revolucionarias (decididamente marxistas) y más

\footnotetext{
${ }^{48}$ El comportamiento contrasta con el que adoptó, por ejemplo, la Concentración Nacional Universitaria cuando, en respuesta por el asesinato del marplatense Ernesto Piantoni, ejecutó a cinco personas.

49 Dada la importancia que tuvo en la construcción y difusión de esta imagen, puede destacarse el célebre libro Ezeiza (Verbitsky, 1995, p. 171).

${ }^{50}$ Clases de adoctrinamiento del Partido Justicialista (10 de agosto de 1973). El Territorio, p. 5. Unidad básica en el Cerrito (16 de agosto de 1973). El Territorio, p. 2.

51 El problema que nosotros encontramos en esta categoría es que la idea de revolución estaba ampliamente difundida en el peronismo tradicional. De hecho, uno de los lemas del CO era: "Con Perón por la Revolución Social Justicialista". A nuestro juicio, lo que distinguió al montonerismo fue su propuesta de reorientación socialista del populismo peronista.
} 
confusas y progresivas en Montoneros (inicialmente más populista), en términos generales la "resignificación del peronismo" ensayada por las organizaciones guerrilleras tenía como función "desconocer a otros peronistas", y de ese modo soslayar la incómoda existencia de "cuerpos" peronistas representativos y construir la ficción de "un peronismo despojado de historia" (pp. 280-288).

Este proyecto estratégico de la juventud de orientación socialista nos parece decisivo para entender su conflicto con las estructuras tradicionales del justicialismo y, finalmente, con Perón. En nuestro análisis, ubicar in toto a los actores antimontoneros en una derecha o extrema derecha le debe mucho a los efectos de esa propia operación simbólica. Porque lo que nos preguntamos es ¿en qué medida las posiciones de aquellos sectores políticos que se agrupan en una derecha peronista representaban una novedad con respecto a los lineamientos clásicos del populismo peronista? ¿En qué sentido era Perón más de derecha en 1973 de lo que lo había sido desde 1943? Referirse a los actores peronistas antimontoneros como una derecha peronista demanda, o bien una demostración de un proceso de desplazamiento ideológico con respecto al populismo original, o bien afirmar que el peronismo siempre fue de derecha.

Este último planteo fue el que sostuvo León Rozitchner (2012, p. 264), a fin de destacar que la izquierda peronista ignoró que había sido usada para una estrategia de derecha orquestada por Perón. La estratagema del militar populista habría consistido en exhibirle la vanguardia revolucionaria a "la otra derecha" (la antiperonista), pero solo como un medio de amenaza para negociar su propia posición de poder. Al incorporar categorías psicoanalíticas, Rozitchner se deslizaba a una visión más ambivalente de Perón, que a nuestro juicio resulta teóricamente más rica. A diferencia de otros de sus colegas castrenses, tan interesados como él en defender al sistema capitalista del desborde pulsional de las masas, la sabiduría de Perón habría radicado en su comprensión del "poder dominante de la afectividad". De este modo, en su política Perón puso en juego la dialéctica de una "doble soberanía" (matriarcado y patriarcado, patricios y plebeyos, izquierda y derecha, agregaríamos nosotros). Por ello, para Rozitchner el desafío consiste en explicar cuánto de "masa" había en su personalidad, cuánto "de clandestino, de relegado y de bastardo: de femenino y popular" había en "su estructura oficialista" (pp. 372-374). Esa ambivalencia estructural del peronismo abrevaba, para Gino Germani (2003), en la coexistencia de elementos ideológicos provenientes de las tradiciones de derechas y de izquierdas. Esto era lo que distinguía a los "movimientos nacional-populares" (o "populismos nacionales"), que por ende se resistían a "cualquier clasificación en una dicotomía derecha/izquierda" (p. 114).

Por ende, para dar cuenta de aquellas identidades políticas que en los años setenta mantuvieron una relación de continuidad fundamental con los postulados populistas de los cuarenta y cincuenta, las categorías de peronismo clásico, tradicional o restaurador resultan, en la perspectiva aquí asumida, más explicativas que la de derecha peronista (Denaday, 2017). La referencia a una tradición se nos revela sugerente porque, como lo planteó Hugo Vezzetti (2013), el tipo de autoridad de Perón se puede homologar con la del Padre "que remite al pasado y la filiación". Vezzetti destaca que "el horizonte de las luchas peronistas posteriores al derrocamiento de Perón era el retorno al pasado, a la edad del Padre" (pp. 68-69). Lo cierto es que muchos de los actores peronistas que en los setenta resultan frecuentemente caracterizados como una derecha peronista seguían, en lo fundamental, en línea con 
los viejos planteos populistas. ¿Qué se aprecia al respecto en la ideología del CO chaqueño?

En su discurso pronunciado en el Congreso de la JP del 19 de mayo de 1973, ante la presencia de delegados de la JP de casi todo el interior chaqueño, Sánchez resaltó la adhesión de los presentes a los "sólidos postulados doctrinarios" del justicialismo y al "ejemplo perenne de Evita". Asimismo, convocó a los jóvenes peronistas a ejercer un contralor sobre las nuevas autoridades para defender los intereses del "pueblo trabajador" que, luego de una "lucha histórica", había logrado derrotar a "la oligarquía entreguista" y al "capital extranjero opresor". Bajo una versión humanista y cristiana, en línea con lo sostenido por Perón en La hora de los pueblos, Sánchez llamó a implementar el "socialismo nacional" para "liberarnos de las sinarquías esclavizadoras". ${ }^{2}$ Así, el jefe del $\mathrm{CO}$ chaqueño formuló un discurso de tono radicalizado, pero sin alterar los clásicos parámetros político-ideológicos del populismo peronista.

Otro aspecto caro a la ideología peronista se advierte en la difusión, a través de una solicitada en El Territorio y de pegatinas de afiches callejeros, que el CO hizo de la "Orden" emitida desde Madrid el 18 de mayo de 1973. Esa "Orden", que llevaba la firma del Comando Superior del Movimiento Nacional Justicialista, o sea de Perón, indicaba que no se podía innovar en las estructuras organizativas del peronismo, lo que apuntaba a desautorizar la fundación de agrupaciones de superficie que Montoneros había desplegado desde el mes de abril. ${ }^{53}$ Más allá del contenido coyuntural, tiene significación advertir la importancia que el CO le atribuía a aquello que denominaban como "la verticalidad del mando". ${ }^{54}$ El acatamiento al liderazgo de Perón en calidad de un conductor que dictaba órdenes era un elemento decisivo del marco ideológico del peronismo tradicional. Como lo ha señalado Alberto Ciria (1983, p. 45), el principio de jefatura (o Führerprinzip) encontraba en Perón un origen en sus tiempos de formación castrense. Pero, al igual que había ocurrido en los fascismos europeos, ${ }^{55}$ el "culto al jefe" era consustancial al sistema de ideas peronista y el CO chaqueño se interesaba en resaltarlo.

Este culto al jefe era acompañado en el discurso del CO con una defensa soberanista de la democracia. Así, en el Chaco se permitieron trazar un paralelismo entre Perón y el líder socialista Salvador Allende. Luego de producirse el derrocamiento y asesinato del presidente chileno, Sánchez y Gómez publicaron un comunicado que reivindicó a Allende como uno de "los mártires de la democracia". Los dirigentes del CO chaqueño plantearon que la acción gubernamental de Allende había buscado mejoras sociales para el pueblo chileno "dentro de la paz y la concordia", de la misma manera que décadas antes lo había realizado Perón desde la Secretaría de Trabajo y Previsión. Sánchez y Gómez especulaban con que la victoria de los militares chilenos sería "efímera y fugaz", porque entendían que "las reivindicaciones sociales de los

\footnotetext{
52 La Juventud Peronista eligió en Sáenz Peña sus nuevas autoridades (21 de mayo de 1973). El Territorio, p. 3.

53 Comando Superior Peronista. Orden (19 de mayo de 1973). El Territorio, p. 10.

54 La Juventud Peronista del Comando de Organización y Alberto Brito Lima (22 de julio de 1973). El Territorio, p. 8.

${ }^{55}$ El duce fascista, el Führer nacionalsocialista y el caudillo falangista eran, en su lógica de legitimidad, figuras semejantes al conductor peronista. Para un análisis del "tropismo personalizador" del fascismo, ver Pascal Ory (2012).
} 
trabajadores no se aplastan con cañones ni fusiles". ${ }^{56}$ Se buscaba así homologar al clásico reformismo peronista con la vía pacífica al socialismo: no parece este un discurso ubicado a la derecha del arco político.

Otra fuente que nos permite analizar la posición político-ideológica del $\mathrm{CO}$ en el Chaco es la que nos brindan las palabras pronunciadas por Brito Lima en su visita de mediados de 1974 a la provincia, cuando llegó para ser uno de los oradores en el acto oficial destinado a conmemorar a los mártires de los fusilamientos del 9 de junio de $1956 .{ }^{57}$ En su discurso, Brito Lima ensayó una interpretación histórica en línea con los argumentos revisionistas y ubicó a "los que se retiraron de Plaza de Mayo" ${ }^{58}$ en el bloque de la "antipatria". Según el diputado nacional, el "verdadero ejército montonero" había sido el de Juan Manuel de Rosas y Facundo Quiroga, y lo era entonces el de los trabajadores, "no el de las agencias noticiosas y tapas de revistas". Brito Lima consideraba que era una regla que ninguna revolución escapaba a la contrarrevolución, pero consideraba que los peronistas sabrían contrarrestarla y destacó a la JP chaqueña como un "bastión" contra "la infiltración". ${ }^{59}$ Al día siguiente, en una conferencia de prensa vindicó al "verdadero pueblo de Chaco", compuesto por "los trabajadores auténticos" y no por "sociólogos vestidos de trabajadores". 60

La adhesión al peronismo como un cuerpo doctrinario, su reivindicación como un movimiento político de carácter revolucionario y la exaltación de Perón en calidad de conductor eran ya piezas caras al peronismo tradicional. Asimismo, se advierte que el CO no estaba dispuesto a ceder al montonerismo algunos significantes, como podían ser la reivindicación de las montoneras decimonónicas y la defensa de los intereses obreros. Al contrario, para el $\mathrm{CO}$ el ascendiente de la Tendencia Revolucionaria estaba asociado a una simulación obrerista de militantes universitarios y a una promoción alentada desde ciertos sectores de la prensa. Como se ve, típicas impugnaciones antimarxistas y antipequeñoburguesas de raigambre populista. Observamos así que no se advierte en el discurso del CO chaqueño una inflexión derechista con respecto a los planteos tradicionales del populismo peronista, sino, en todo caso, una versión combativa y romántica de este.

\section{Consideraciones finales}

Al estudiar grupos como el CO cabe preguntarse: ¿cuán novedosa era, en verdad, desde una mirada panorámica de la historia del peronismo entre los años cuarenta y setenta, la presencia de grupos irregulares y de mecanismos policíacos de control político y social? Si bien, prima facie, la idea de una "solución policial" a la insurgencia guerrillera remitía al imperio de la ley, el problema radica, como hemos visto, en la ambigüedad con que Perón y las fuerzas de seguridad entendían esta cuestión. En tanto se trataba de un político que ya había presidido el país, una mirada a sus anteriores gobiernos resulta ilustrativa: ni la intervención policial en la política, ni la

\footnotetext{
${ }^{56}$ Solidaridad con Chile. Comando de Organización (18 de septiembre de 1973). Norte, p. 9.

57 Emotivo homenaje a los caídos en el 56 (10 de junio de 1974). Norte, p. 1. En dicha fecha habían acontecido una serie de fusilamientos de partidarios peronistas en el marco de la represión del levantamiento cívico-militar del general Juan José Valle.

${ }^{58}$ En referencia a la ruptura pública entre Montoneros y Perón ocurrida el $1^{\circ}$ de mayo de 1974.

${ }^{59}$ Lo dijo Bittel en el acto oficial. "O con Perón, o contra Perón" (10 de junio de 1974). Norte, p. 12.

${ }^{60}$ Brito Lima: son fieras acorraladas (11 de junio de 1974). Norte, p. 20.
} 
presencia de irregulares armados (Alianza Libertadora Nacionalista) habían estado ausentes en el sistema de gobierno peronista de los cuarenta y cincuenta. De este modo, en forma semejante a lo que acontece con la cuestión ideológica, la imagen de un peronismo setentista desvirtuado por figuras o grupos siniestros contribuye al mito de un cambio histórico que, en lo sustancial, no se aprecia. En nuestra perspectiva, las concepciones ideológicas y las prácticas políticas y estatales del movimiento peronista reclaman ser interpretadas entre los años cuarenta y setenta más en términos de continuidades que de rupturas.

La presencia en los setenta de grupos como el CO se hace más comprensible en la intelección de la sucesión de formaciones partisanas que acompañaron el derrotero del populismo peronista, antes que en el presunto advenimiento de grupos presentados desde una exterioridad político-ideológica. Por caso, caracterizar a la seguridad del palco oficial en Ezeiza en términos de unos "grupos de extrema derecha" que estaban a "las órdenes de Osinde y Rucci" (Svampa, 2007, p. 402) construye un registro narrativo que oscurece el trasfondo real de la dinámica política. Porque si esas piezas clave del dispositivo de Perón son ubicadas en la extrema derecha, entonces habría que colocar allí al propio líder justicialista.

No resulta fácil sostener, sin embargo, que en 1973 Perón haya estado ubicado más a la derecha de lo que lo estaba al momento de ser derrocado en 1955. El líder justicialista se mostraba, en términos político-institucionales, más pluralista que otrora. En lo económico-social, el plan impulsado por José Ber Gelbard era más intervencionista y redistributivo que el que se venía aplicando, bajo el diseño de Alfredo Gómez Morales, cuando triunfó la Revolución Libertadora. Quizá sea exagerado afirmar, como lo hace Ricardo Sidicaro (2010, p. 116), que el proyecto de 1973 haya tenido posiciones relativamente "más cuestionadoras del orden económico y social capitalista". Aunque ninguno parecía proponerse cuestionar las bases del sistema capitalista, es cierto que el de 1973 estaba menos apegado a la ortodoxia económica, de la que Gómez Morales seguía siendo más celoso también en los setenta. En lo que hace al CO, en un congreso nacional de abril de 1974, con la presencia de los dirigentes del Chaco y de otras provincias, votó entre las resoluciones apoyar el Plan Trienal de Gelbard. ${ }^{61}$ Esto los diferenciaba de la posición del lopezreguismo, inmerso en una lucha palaciega con el ministro de Economía.

Siguiendo a Emilio De Ipola y Juan Carlos Portantiero (1989, p. 23), entendemos que conceptualmente no operaba una relación de continuidad, sino de ruptura entre el populismo y el socialismo. Al respecto, Mario Firmenich señalaba en una charla interna de fines de 1973 que la "ideología de Perón es contradictoria con nuestra ideología porque nosotros somos socialistas, es decir, para nosotros la Comunidad Organizada, la alianza de clases, es un proceso de transición al socialismo". ${ }^{62}$ En este sentido, la naturaleza del conflicto con los jóvenes montoneros se aprecia mejor atendiendo a su contradicción con la "rama histórica" del peronismo político y sindical, como lo advierte Servetto $(2010$, pp. 68,214$)$ al internarse en un universo empírico más rico de lo que sugiere la dicotomía izquierda-derecha.

En lo relativo a sus prácticas políticas, hemos visto que el CO fue una agrupación partisana que no llevó al extremo la lógica terrorista, cuestión que en el

\footnotetext{
${ }^{61}$ Comando de Organización: gestiones en la capital (14 de abril de 1974). Norte, p. 6.

62 Firmenich, M. (1973). Esa charla de la Conducción Nacional se publicó en el libro compilado por Roberto Baschetti (1996, p. 274).
} 
Chaco se visualiza con particular claridad. Este asunto nos interesa porque permite someter a discusión algunas imágenes consolidadas sobre los años setenta. Vezzetti (2013) afirma que, "sobre todo después de la masacre de Ezeiza y el nacimiento de la Triple A", fueron "los grupos de ultraderecha y las redes parapoliciales" las que aportaron "la parte más desmesurada" en la "escalada de barbarie" (p. 163). Esto podría quizá sostenerse, aunque no sin mediar algunos considerandos para los casos de las bandas del Ministerio de Bienestar Social, la Concentración Nacional Universitaria y los guardaespaldas de la Unión Obrera Metalúrgica. ¿Pero vale para el CO, dada su extensión militante una agrupación decisiva en ese conglomerado? En general, sería dudoso aseverar tal cosa, y en la provincia del Chaco en particular no se corrobora.

En el mismo sentido, y para finalizar, el presente estudio de caso exhibe las frecuentes tensiones que suelen darse entre los registros de la memoria y la historia. Una voz de los derechos humanos del 2009 menciona a Sánchez como "un asesino de la Triple $A^{\prime \prime},{ }^{63}$ mientras una investigación ubica el ataque al comedor universitario por parte del $\mathrm{CO}$ chaqueño en una saga de hechos de violencia atribuidos a lo que sugiere el título del libro: Perón y la Triple $A$ (Bufano y Teixidó, 2015, p. 406). Pero, en los hechos fácticos de la historia, lo cierto es que Sánchez no perteneció a la Triple $A^{64}$ ni fue un asesino. El problema que se esconde por detrás de estas generalizaciones es que no se condicen con la pluralidad del peronismo oficialista de los setenta. Esta también se aprecia entre los actores partisanos, cuyo accionar constituye un equívoco reducir a lo que, con cierta vaguedad, suele nominarse como Triple A. Por tanto, es importante reparar en la heterogeneidad que se aprecia entre los actores partisanos vinculados al peronismo oficialista. Esta diversidad se advierte tanto en la modalidad y la intensidad de la violencia, en las gradaciones entre lo irregular-ilegal y lo regularlegal en las prácticas políticas, así como en la relación mantenida con el cuerpo de ideas provisto por el populismo peronista.

\section{Referencias bibliográficas}

1. Altamirano, C. (2011). Peronismo y cultura de izquierda. Siglo XXI.

2. Anzaldi, P. (2016). Los años 70 a fondo. Guerrilleros, militares y familiares. Reportajes inéditos a los protagonistas de la Argentina violenta. SB.

3. Arias, M. y Heras, R. (1993). Carisma disperso y rebelión: los partidos neoperonistas. En S. Amaral y M. B. Plotkin (Comp.) Perón, del exilio al poder (pp. 95-125). Cántaro.

\footnotetext{
${ }^{63}$ María del Pilar Cachaza de Goya, ejemplo de esperanza y de lucha, recuperó a su nieto después de 30 años de búsqueda (marzo de 2009). Abuelas de Plaza de Mayo, Mensuario, Año X, No 78. https://www.abuelas.org.ar/. El hijo de esta abuela de Plaza de Mayo se encontró entre los detenidos en 1975 por el asesinato de Sánchez y, en su caso, resultó absuelto hacia fines de año.

${ }^{64}$ En el Chaco recién a fines de 1975 explotó una bomba que se atribuyó la Triple A y comenzó a actuar un denominado Comando Nacionalista Azul y Blanco. Para entonces, Sánchez estaba muerto y no se aprecia ningún vínculo entre estos grupos y el CO. Las amenazas en el Chaco (27 de septiembre de 1975). Norte, p. 6. Chaco. Bombazo en Resistencia (28 de septiembre de 1975). Norte, p. 2.
} 
4. Bucciarelli, M. (2009, 8 de octubre). La Patagonia argentina como Territorio Nacional. Perspectivas de análisis [ponencia]. VIII Congreso de Historia Social y Política de la Patagonia Argentino-Chilena, Chubut, Argentina. http://historiapolitica.com/datos/biblioteca/ariasb2.pdf

5. Bufano, S. y Teixidó, L. (2015). Perón y la Triple A. Las 20 advertencias a Montoneros. Sudamericana.

6. Ciria, A. (1983). Política y cultura popular. La Argentina peronista 1946-1955. De la Flor.

7. De Ipola, E. y Portantiero, J. (1989). Lo nacional-popular y los populismos realmente existentes. En E. De Ipola, Investigaciones políticas (pp. 21-36). Nueva Visión. (Original publicado en 1981).

8. Denaday, J. (2016). Comando de Organización: un peronismo plebeyo, combativo y nacionalista (1961-1976). Quinto Sol, 20 (1), pp. 1-21. http://dx.doi.org/10.19137/qs0832

9. Denaday, J. (2017). Notas para el debate historiográfico sobre el peronismo de los setenta. Pasado Abierto, 5, 115-136. https://fh.mdp.edu.ar/revistas/index.php/pasadoabierto/article/view/2192/0

10. Firmenich, M. (1973). Charla de la Conducción Nacional ante las agrupaciones de los frentes. En R. Baschetti (Comp.) (1996). Documentos1973-1976. De Cámpora a la ruptura (pp. 258-311). De la Campana.

11. Germani, G. (2003). Autoritarismo, fascismo y populismo nacional. Temas. (Original publicado en 1978).

12. Leoni, M. S. y Solís Carnicer, M. (2015). Peronismo, diseño institucional y centralización política. Un análisis a partir de dos espacios subnacionales argentinos: Corrientes y Chaco (1946-1955). Iberoamericana, XV (60), 61-79. https://doi.org/10.18441/ibam.15.2015.60.61-79

13. Macor, D. y Tcach, C. (2013) (Comp.) La invención del peronismo en el interior del país II. Universidad Nacional del Litoral.

14. Macor, D. y Tcach, C. (Comps.) (2014). La invención del peronismo en el interior del país. Universidad Nacional del Litoral. (Original publicado en 2003).

15. Maeder, E. (1996). Historia de/ Chaco. Plus Ultra.

16. Marcilese, J. (2017). El peronismo bonaerense: facciones, lealtades y tensiones. De la Convención de Avellaneda a la Revolución Argentina (1965-1966). Estudios Sociales, 34, 11-38. https://doi.org/10.14409/es.v53i2.7024 
17. Michanie, M. (2018). Maestro de maestros. Instituto Nacional de Cine y Artes Audiovisuales.

18. Nadra, F. (1974). Un año de gobierno peronista. Sílaba.

19. Ollier, M. (2006). Golpe o revolución. La violencia legitimada, Argentina 1966/1973. Universidad Nacional de Tres de Febrero. (Original publicado en 1986-1989).

20. Ory, P. (2012). Del fascismo. Nueva visión. (Original publicado en 2003).

21. Rozitchner, L. (2012). Perón: entre la sangre y el tiempo. Lo inconsciente y la política. Biblioteca Nacional. (Original publicado en 1984).

22. Ruffini, M. (2005). Peronismo, territorios nacionales y ciudadanía política. Algunas reflexiones en torno a la provincialización. Avances del Cesor, 5, 132148. http://biblioteca.clacso.edu.ar/Argentina/cehepycuncoma/20110414122415/Ruffini.pdf

23. Schmitt, C. (2013). Teoría del partisano. Acotación al concepto de lo político. Trotta. (Original publicado en 1963).

24. Servetto, A. (2010). 73/76. El gobierno peronista contra las "provincias montoneras". Siglo XXI.

25. Sidicaro, R. (2010). Los tres peronismos. Estado y poder económico. Siglo XXI. (Original publicado en 2002).

26. Solís Carnicer, M. y Maggio, M. (2019). Posibilidades y limitaciones del uso de la prensa como fuente para la reconstrucción de la historia política en el nordeste argentino: algunas notas sobre Corrientes y Chaco (Primera mitad del siglo XX). Folia Histórica del Nordeste, 34, 151-168. https://ri.conicet.gov.ar/handle/11336/121186

27. Svampa, M. (2007). El populismo imposible y sus actores, 1973-1976. En D. James (Dir.) Violencia, proscripción y autoritarismo (1955-1976) (pp. 381-438). Sudamericana. (Original publicado en 2003).

28. Verbitsky, H. (1995). Ezeiza. Planeta. (Original publicado en 1985).

29. Vezzetti, Hugo (2013). Sobre la violencia revolucionaria. Memorias y olvidos. Siglo XXI. (Original publicado en 2009). 